\title{
Smart Smoke Control as an Efficient Solution for Smoke Ventilation in Converted Cellars of Historic Buildings
}

\author{
Wojciech Węgrzyński (D*, Grzegorz Krajewski and Grzegorz Kimbar, Fire \\ Research Department, Instytut Techniki Budowlanej, Warsaw, Poland
}

Received: 17 March 2020/Accepted: 4 September 2020/Published online: 23 September 2020

\begin{abstract}
The paper is focused on the topic of smoke control in a confined, underground cellar area of a historical building, that is undergoing conversion to a restaurant. Similar venues were host to some of the most devastating fires in history. We have investigated the performance of a novel solution, "smart smoke control (SSC)", and compared its performance with "traditional" smoke venting solution. The investigation was based on CFD simulations performed in a commercial code ANSYS Fluent, modified with user-defined functions to include for the steering algorithm of the SSC. The simulation results for a traditional system were unsatisfactory, while the SSC removing substantially more smoke (approx. 50\% more) has provided tenable conditions over the whole course of the analysis. The results indicate that smoke control solutions based on the adaptive performance of the smoke exhaust fan, based on the conditions within the protected premise, can be favourable for compartments with the limited size of the smoke reservoir or limited space available for ducts. These findings are also true for existing buildings, where it may be advantageous to replace the existing smoke control solution with SSC. Future investigations should include full-scale experiments, and improvements in the simple algorithms used so far.
\end{abstract}

Keywords: Fire, Smoke control, Ventilation, Smart fire systems, Historical buildings

\section{Introduction}

\subsection{Challenges in Fire Safety of Cellars Converted to Utilities}

Refurbishment and conversion of historic buildings is a popular trend in the architecture. Old town buildings are favourably located in city centres, which promotes the change of building occupation from residential and storage to hotels, tourism and services. The cost of land and lack of available plots for new development promote the use of every part of the historic buildings - including ones that were located underground and primarily used for storage (in Poland primarily for coal and wood storage). The new occupation of the underground venues after conversion can include restaurants, pubs and music clubs. This is a radical

\footnotetext{
* Correspondence should be addressed to: Wojciech Węgrzyński, E-mail: w.wegrzynski@itb.pl
} 
change in the use of a premise-from a remote area without constant human presence into a crowded area with hundreds of occupants.

Enclosed nightclub type venues were house to some of the biggest fire disasters, including The Cocoanut Grove Nightclub fire in Boston (1942, 492 deaths) [1], The Station Nightclub fire in Warwick (2003, 100 deaths) [2] or KISS Nightclub fire in Santa Maria (2013, 242 deaths) [3]. Limited ventilation, lack of windows, complex compartmentation and possibly non-conforming users are key factors influencing the high risk of fire in such enclosures.

\subsection{Life Safety of Underground Club Venues}

The provision of life safety for occupants in case of a fire of an underground club venue is based on multiple technical and organisational solutions. These technical requirements will differ depending on local building laws [4], and may include: flammability requirements for wall/floor linings and the furnishings; provision of multiple escape routes of limited length, with a certain width and height; protection of the evacuation stairwells against smoke (either smoke removal or pressurization); automatic smoke detection and sound/voice alarm systems etc. In many countries underground clubs must be protected with water-based fixed firefighting systems (although, in case of the object presented in this study this was not obligatory). Furthermore, in many building law systems, as in Poland [4], smoke control systems are required in such areas as one of its primary fire-safety features. The design of the systems is performance-based, which means that tenability criteria must not be exceeded on the evacuation routes during the evacuation time. This approach is more commonly known as the Available and Required Safe Evacuation Time (ASET/RSET) analysis [5, 6]. Finally, the technical requirements are accompanied by organisational requirements, related to the fire-fighting equipment, personnel training and safety procedures.

The list presented above is not exhaustive, and all of the mentioned elements are critical for the provision of fire safety in the venue. In this paper, the focus is put on the smoke control solutions and their ability to provide tenable conditions on the evacuation routes, within the evacuation time (RSET).

\subsection{Smoke Control Systems}

Smoke control systems are a wide group of technical solutions that, in principle, aim to reduce the threats to occupants coming from smoke and combustion products. Klote [7] has defined five groups of physical mechanisms, on which the technical solutions for smoke control are based: (1) compartmentation, (2) dilution, (3) pressurization, (4) airflow and (5) buoyancy. In this paper, we are discussing mechanical Smoke and Heat Exhaust Ventilation Systems (SHEVS, [8]), which are also referred to as venting systems. In this case study, the venting system acts as a combination of (5) buoyancy and (4) airflow. The goal of the operation is to maintain the stratified buoyant smoke layer underneath the ceiling of a protected premise, that allows undisturbed evacuation conditions at the evacuation route beneath. 
In this paper a novel hypothetical smoke control solution is used-the so-called "smart smoke control (SSC)", proposed for the first time in [9] and described in [10]. The smart smoke control concept is based on the idea that the system may adapt its momentary volumetric capacity dependant on the density of the removed air (a mixture of air and smoke) so that the mass capacity of the exhaust is constant in time. Contrary to SSC, standard smoke control solutions are designed for a specified constant volumetric capacity of exhaust, designed for operating pressure in ambient conditions. This means that the smoke exhaust points have a fixed value of the volumetric capacity, which is constant independently of the smoke temperature. This standard solution will be further referred to as "the traditional solution". For the purpose of this work, both of the solutions are modelled with a simplified 'constant velocity' boundary condition, that omits the effects of the temperature on the fan-curve. In real world engineering additional complexity would be introduced with the choice of the correct operation point of the fans, and the change to that point with the increased temperature. However, based on previous high-temperature testing [9] and conditions mentioned in EN 12101-3 [11], we found this simplification to be justified for the purpose of illustrating the fundamental differences in tenability between SSC and traditional solution.

\section{Challenges in Smoke Control of Historical Underground Venues}

The specific difficulties related to the design of an efficient smoke control in converted historic cellars are (a) lack of space for the smoke reservoir; (b) lack of space for horizontal and vertical exhaust ventilation ducts; (c) difficulties in provision of the make-up air.

\subsection{A Limited Volume of the Smoke Reservoir}

Fire smoke forms a buoyant layer underneath the ceilings of compartments. This is a consequence of the differences in density between hot smoke and ambient. The volume underneath the ceiling where the smoke is expected to gather is referred to as the smoke reservoir. If the smoke produced by the fire overfills the smoke reservoir, the smoke layer interface height will decrease, and eventually, fall below the height that allows for occupant evacuation. In low and narrow compartments, the smoke reservoir volume is limited, and thus its capability to accumulate smoke is hindered.

In an optimal scenario, the smoke exhaust rate from the smoke reservoir matches the smoke production, and the smoke layer interface height can be continuously kept above evacuation routes, so it does not affect the evacuees (besides the radiant heat from the layer) [8], Fig. 1. However, the smoke exhaust requires the smoke layer of a certain depth to maintain efficient removal of the smoke. If smoke exhaust velocity is too high or the smoke layer not deep enough, plugholing phenomena may occur (Fig. 2a) [11]. In plugholing cold air is removed through the layer of hot smoke by the exhaust point, making the smoke venting inefficient. Thus, in compartments with low-ceiling, and consequently shallow 


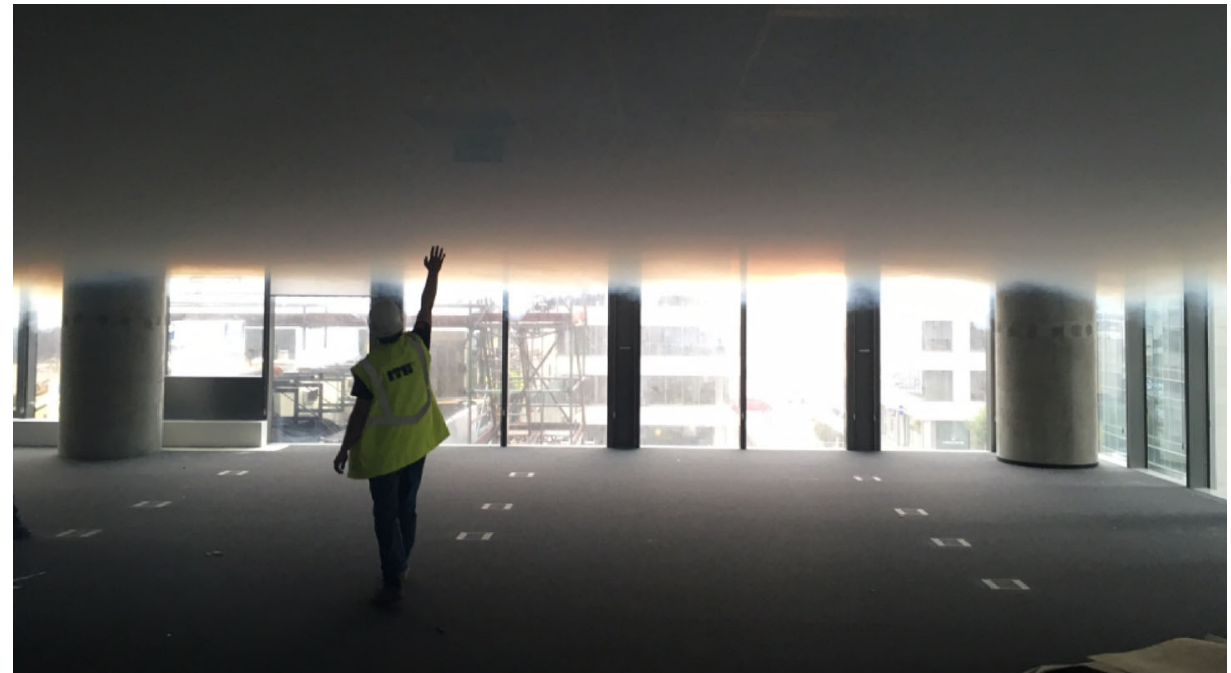

Figure 1. The hot smoke layer above an evacuation route in an open plan office (in a hot smoke test).

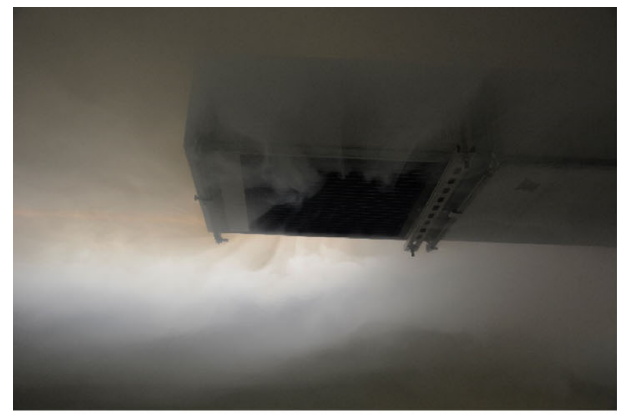

(a)

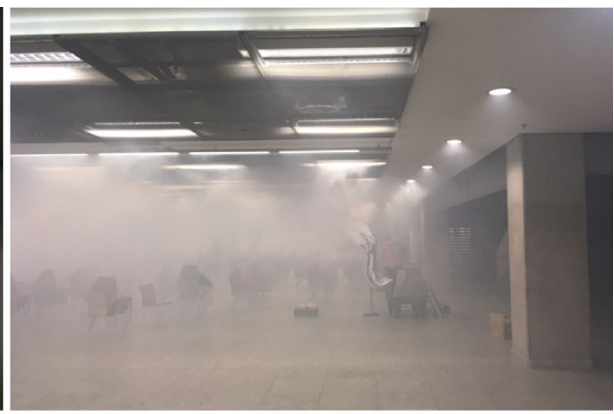

(b)

Figure 2. (a) The phenomenon of plugholing-cold air is removed through an exhaust point from below the layer of hot smoke; (b) disturbed smoke layer-no sharp layer interface visible anymore, smoke present in the whole height of the compartment.

smoke-reservoir height, low smoke exhaust velocity must be maintained to for efficient removal of the smoke.

\subsection{Location of Horizontal Ducts}

Efficient smoke control requires uniform smoke exhaust from the whole smoke reservoir. If the smoke reservoir has a complex architecture, the exhaust points must be spread as evenly as possible, to provide similar exhaust performance in any location of the protected compartment. This is obtained by distributing hori- 
zontal ducts through the compartment, on which ventilation exhaust points are located. The design airflow velocity (the Authors have experience with velocities ranging between $5 \mathrm{~m} / \mathrm{s}$ and $12 \mathrm{~m} / \mathrm{s}$ ) is chosen depending on the pressure point of the fan, the complexity of the installation and the anticipated acoustic characteristic of the system. As one horizontal duct may serve multiple exhaust points, it is common to have large crossections that effectively cover large part of the ceiling area, Fig. 3. Thus, the available space for horizontal ducts can become a limiting factor for the smoke control design.

\subsection{Location of Vertical Ducts}

The smoke successfully removed from the compartment must be transported outside of the building, which usually is performed through vertical ducts and shafts. Provision of new shafts usually requires intrusion to the antique structure of a historic building. This may, however, be prohibited by the Historical Preservation Authorities. In consequence, the building designer may be limited to pre-existing shafts, which were not designed with smoke-control function in mind. Furthermore, construction of new vertical ducts takes some of the gross leasable area (GLA) on all floors they cross, thus reducting the economic return from the investment. The available exhaust ducts (or space of new ducts) may be another limiting factor for the smoke control design.

\subsection{Provision of Make-Up Air}

Underground compartments may be considered as a sealed thermodynamic systems. If the air and hot smoke are mechanically removed from the compartment, the same mass of air must be supplied to it. Otherwise, a significant change in pressure will occur. In the latter case, the pressure-point of the exhaust fan will quickly change, and therefore will stop removing the smoke from the compart-
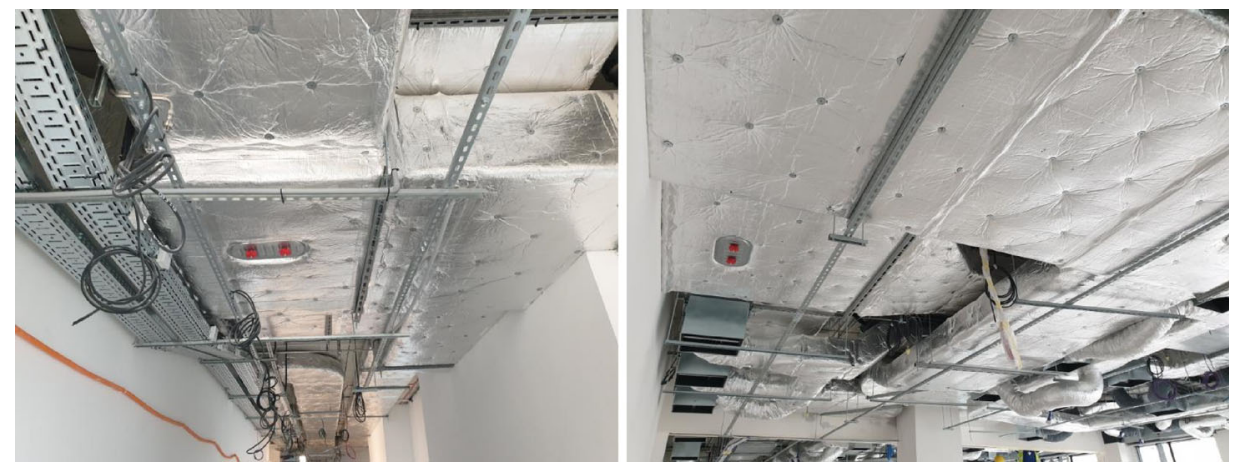

Figure 3. Ductwork underneath a ceiling of a corridor (left) and office space (right). A large amount of ducts reduces the available space for the smoke reservoir. Due to physical limitations, the space available for ducts may be a limiting factor for the design of a smoke control system (Courtesy of R. Brzozowski). 
ment. Furthermore, a large difference in internal and external pressure may prohibit opening the evacuation doors, effectively trapping the occupants in the engulfed cellar. As illustrated by this example, the provision of supply air is as important, as removal of the smoke.

Two distinct challenges emerge with the provision of air in underground, enclosed compartments. Firstly, there are no natural openings that could fulfil this role, or they are located near the ceiling (within the smoke reservoir). If the air supply points are placed in a wrong location, the smoke in the reservoir may be disturbed by forced air flows that cause turbulent mixing of the hot smoke and ambient air. The consequence of mixing is the loss of buoyancy by the smoke, which leads to accelerated decline of the smoke layer and may lead to obscuring parts of the evacuation routes by dense, cold smoke (Fig. 2b). These problems are amplified in narrow compartments, where air streams introduced by the points of the air supply may rebound upwards on walls directly into the smoke reservoir [12].

Secondly, the air must be supplied with low velocity (preferably $<1 \mathrm{~m} / \mathrm{s}$ ) not to disturb the layer buoyancy $[13,14]$. This low velocity requires use of large inlets, which often becomes another limiting factor for the design of the smoke control system.

\section{Use of Smart Smoke Control in Historic Buildings}

\subsection{Smoke Exhaust Ventilation in Elevated Temperatures}

An idea of smart smoke control system emerged from the realization that the performance of the smoke exhaust system in ambient conditions (ones for which the system is designed and commissioned) is considerably different than in elevated temperature. Figure 4a illustrates a compartment, with a combination of natural air supply inlets and mechanical air supply and traditional exhaust with constant volumetric capacity. If one considers the fire development in this compartment in the function of time, it is expected that the air temperature will change with the change of the Heat Release Rate (Fig. 4b), Eq. 1.

$$
\Delta T=\frac{\dot{Q}}{\dot{m}_{p} c_{p}}
$$

where $\Delta T$ is the temperature rise $(\mathrm{K}), \dot{Q}$ is the heat release rate $(\mathrm{kW}), \dot{m}_{p}$ is the mass flow of smoke $(\mathrm{kg} / \mathrm{s})$ and $c_{p}$ is the specific heat of air at $\mathrm{s}$ constant pressure $(1.01 \mathrm{~kJ} / \mathrm{kgK})$.

In the traditional system, the volumetric capacity of the exhaust will reach a specific value, and will remain constant for the time of operation, Fig. 4c. As the air changes its density with the rise of temperature (Eq. 2), the mass flow of this exhaust point will decrease (Eq. 3), Fig. 4d. 


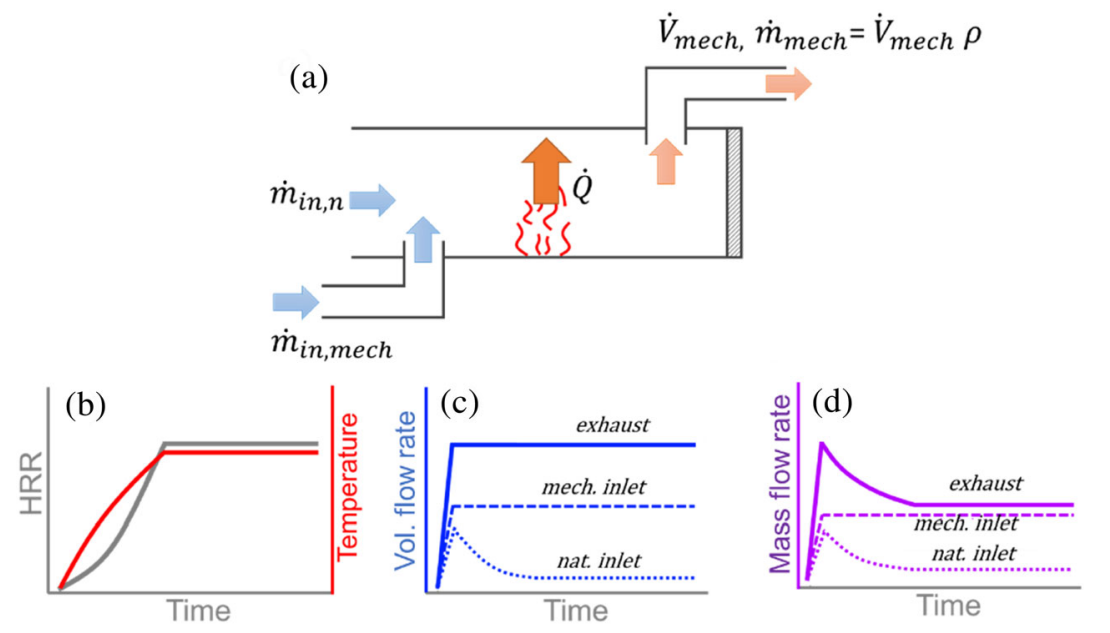

Figure 4. (a) Schematic representation of the flow of air within an enclosed compartment with mechanical venting and a fire; (b) Heat Release Rate (a) and temperature evolution in the function of time; (c) volumetric flow rate at exhaust and inlet points; (d) mass flow rate at exhaust and inlet points.

$$
\begin{aligned}
& \rho=\rho_{\text {amb }}\left(\frac{T_{a m b}}{\Delta T+T_{a m b}}\right) \\
& \dot{m}_{\text {mech }}=\dot{V}_{\text {mech }} * \rho
\end{aligned}
$$

where $\rho$ is the density of air $\left(\mathrm{kg} / \mathrm{m}^{3}\right), \rho_{\text {amb }}$ is the ambient air density $\left(\mathrm{kg} / \mathrm{m}^{3}\right), T_{a m b}$ is ambient temperature $(\mathrm{K}), \dot{m}_{\text {mech }}$ is the mass flow at mechanical exhaust $(\mathrm{kg} / \mathrm{s})$ and $\dot{V}_{\text {mech }}$ is the volumetric flow of the mechanical exhaust $\left(\mathrm{m}^{3} / \mathrm{s}\right)$.

The amount of air (mass and volume) delivered through mechanical air supply points can be considered as constant in time, while the amount of air supplied through natural air supply will be the difference between the mass flow rate at the exhaust and at the mechanical inlets, Eq. 4.

$$
\dot{m}_{\text {mech }}=\dot{m}_{i n, \text { mech }}+\dot{m}_{i n, n}
$$

The observed decrease of mass flow rate at exhaust points with the increase of the smoke temperature (Fig. 4d) was interpreted as a potential "reserve" of the system. Lower mass flow rate at elevated temperatures results in lower operating pressure, lower operating power and lower strain on the system elements. It means that in elevated temperature, the system operates below the operating parameters, for which it was designed. 


\subsection{The Idea of Smart Smoke Control}

In the Smart Smoke Control solution (Fig. 5a), the volumetric operating capacity of a system is determined based on the measured temperature of the exhausted smoke, so that the mass flow rate of exhaust points is maintained as constant in the operation of the system, Fig. 5b, c.

To maintain the mass flow rate as constant, the volumetric capacity of the system must increase (Fig. 5c), following the increase of the temperature of the smoke (Fig. 4b). This results in maintaining close to a constant value of operating pressure (Fig. 5d) and shaft power of the fan (Fig. 5e), indicating that the system operates with a similar strain in elevated temperatures as in ambient.

To implement this solution in practice (in our case in the CFD analyses), a following simple steering algorithm was developed, Fig. 6. In every time step of the analysis, and in the real world in continuous time, the system decides on the optimal volumetric exhaust capacity of the system. The regulation curve is defined before the analysis, based on the expected change of the air density with the temperature. To prevent oscillatory behaviour, the temperature used in the calculation is a moving average; in our case averaged over the last $5 \mathrm{~s}$. A more detailed explanation of the idea of the operation of the SSC and explanation of the User Defined Function that represents it in ANSYS Fluent simulations was given in [9].

\subsection{Expected Benefits of the Smart Smoke Control}

The SSC should allow for an increase of the volumetric flow of smoke removed from the cellar as the fire grows. This is a direct consequence of increased volumetric flow rate of the fan unit, compared to a traditional solution. However, contrary to traditional solution, in SSC this increased volumetric flow may be obtained with smaller ducts, as due to change in air density with the change of temperature, the air may be transported with higher velocity through ducts. If the available space for ducts is the limiting factor for the system (as in the case study), the smart smoke control system can remove more smoke compared to a traditional solution with the same ductwork.

(a) Exhaust fan

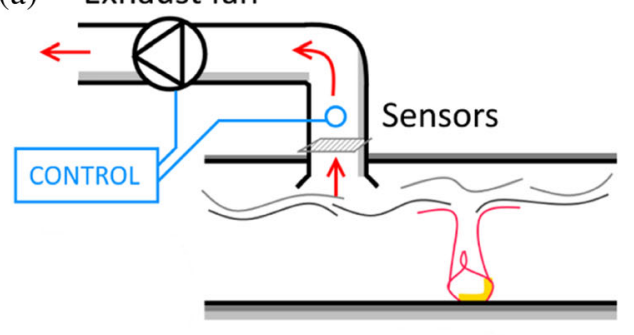

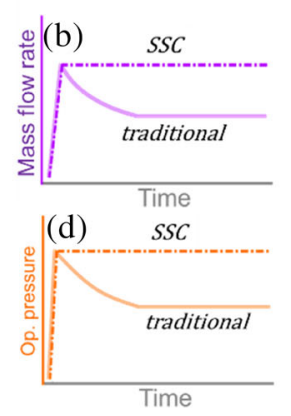

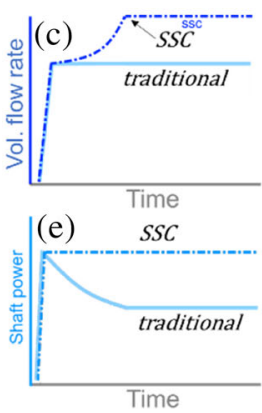

Figure 5. (a) Schematic representation of the smart smoke control system idea; (b) mass flow rate at the exhaust point; (c) volumetric flow rate at the exhaust point; (d) operating pressure; (e) shaft power. 


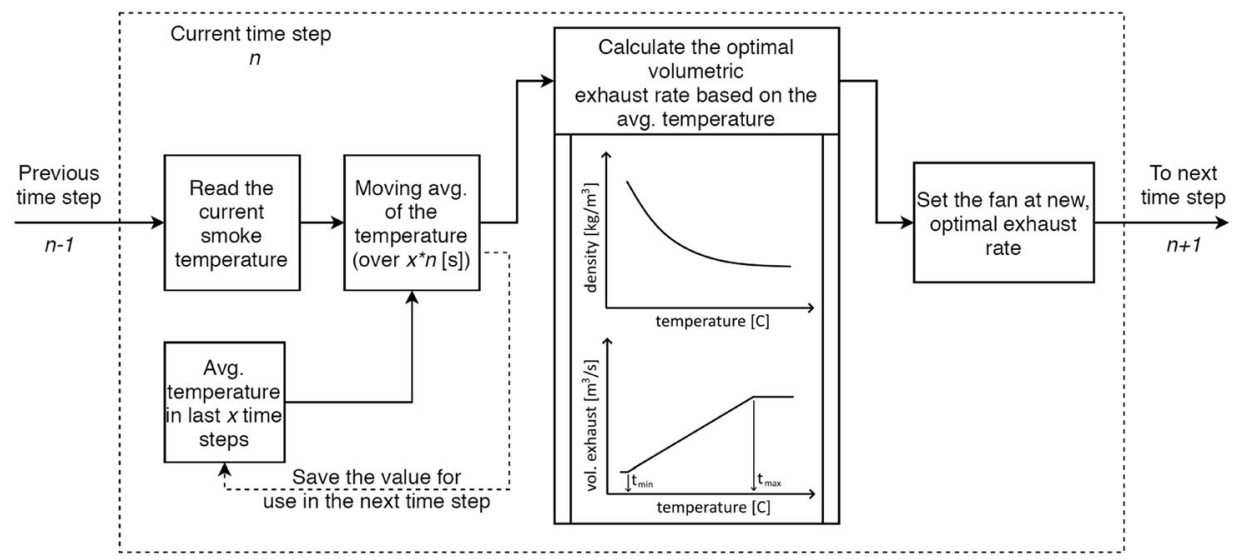

\section{Figure 6. Flowchart of the smart smoke control steering algorithm (simplified).}

In a car park ventilation case study [9] the increase of the performance was between $25 \%$ and $41 \%$ of the traditional system capacity.

The expected consequences of increased volumetric flow rate (that allows for maintaining constant mass flow rate at different smoke temperatures) include prolonged RSET time, lower smoke temperaure and improved environmental conditions over evacuation routes. This working hypothesis was verified with use of Computational Fluid Dynamics (CFD) modelling in a case study based on real project of conversion of a historical cellar into a music-club type venue.

\subsection{Smart Smoke Control and Sprinkler Systems}

The performance of SSC is reliant on the decrease of the smoke density, which is a consequence of heat release in the fire. If the building is protected with waterbased fixed firefighting systems (such as sprinklers), the average smoke temperature may be expected to be lower, than the sprinkler activation temperature [8]. In this case, the main advantage of the SSC over traditional systems (ability to remove substantially more air) is hindered, and as the benefits of using this solution are questionable. However, in Authors opinion, the use of sprinklers in underground venues combined with the traditional solutions for smoke control may provide better life safety, than the use of SSC in an unsprinklered setup.

\section{Case Study}

\subsection{The Building}

An example of an unsprinklerred historical cellar to be converted into a musicclub type venue is shown on Fig. 7. This underground space consists of connected cellars of two buildings, with an overall size of $16 \mathrm{~m} \times 35 \mathrm{~m}$. The building consists of 10 compartments for guests, and 5 other additional compartments, connected together by multiple corridors. The total area of the cellar was approx. 


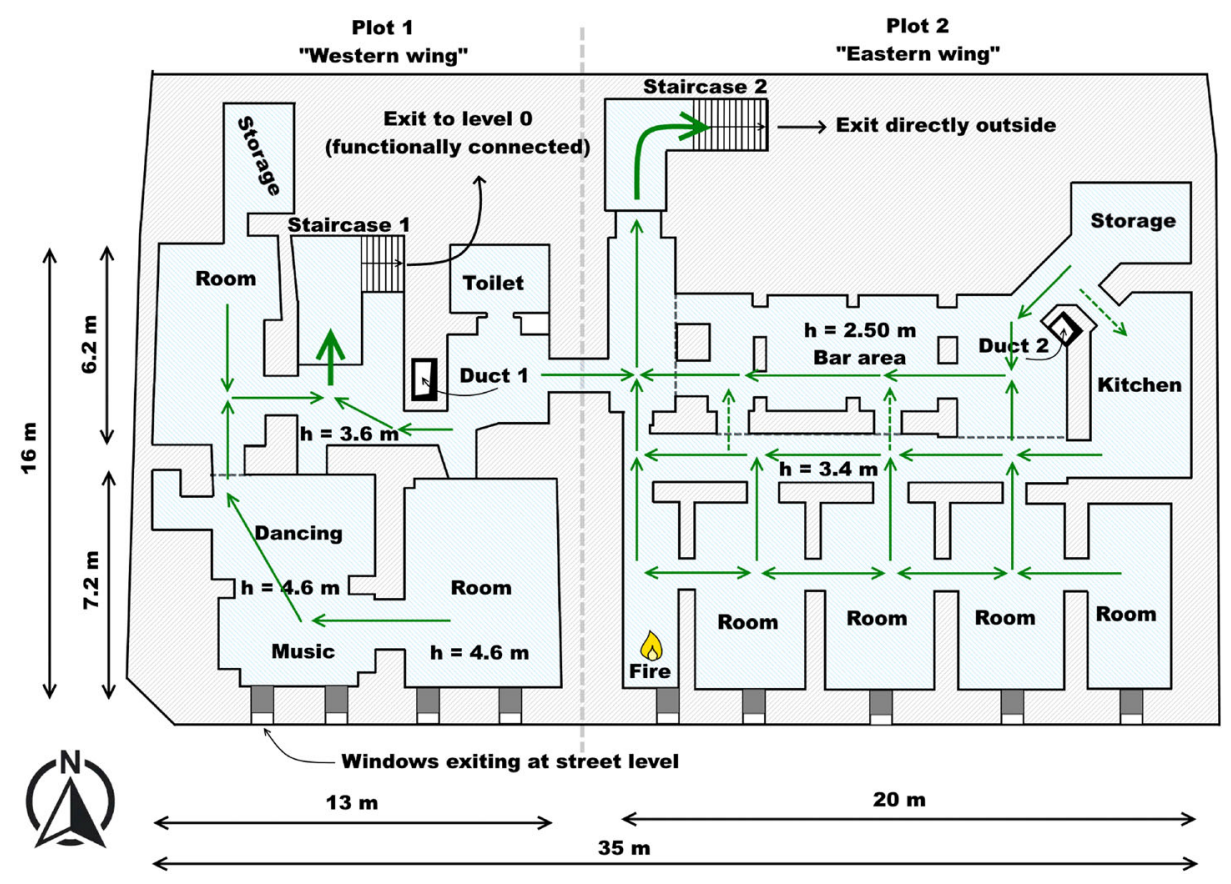

Figure 7. General scheme (simplified) of a cellar of historic building undergoing conversion to a restaurant and a music club. Green arrows indicate main evacuation paths (dashed lines indicate alfernative paths).

$440 \mathrm{~m}^{2}$. The height of compartments varies from $3.60 \mathrm{~m}$ to $4.60 \mathrm{~m}$ in the western wing, and from $2.50 \mathrm{~m}$ to $3.40 \mathrm{~m}$ in the eastern wing.

The evacuation from the underground level is possible through two evacuation staircases (one in each wing). Total number of planned occupants (personell and guests) was 190 people. The evacuation time was estimated by means of computer modelling with buildingExodus model and PD 7974-6 guidelines [15]. Dependant on the scenario and chosen pre-evacuation delay the calculated evacuation time was 4 to $6 \mathrm{~min}$. Applying a margin of safety of $1 \mathrm{~min}$, the resulting RSET was 5 to $7 \mathrm{~min}$. The details of the evacuation analyses are not in the scope of this paper.

\subsection{Assumptions for the Smoke Ventilation Systems}

The smoke exhaust in the building was possible only through a vertical shaft in the central part (the area between the buildings, exhaust duct \#1) and a shaft near the western end of the cellar (future bar area, exhaust duct \#2). The air was removed from the evacuation corridors, and to some extent directly from compartments. The air supply was possible through small windows on the southern façade, which are connected with ducts to the supply points near the compartment floors. The cellar has different floor and ceiling heights, which were represented in detail in the numerical model, as shown in Fig. 8. 


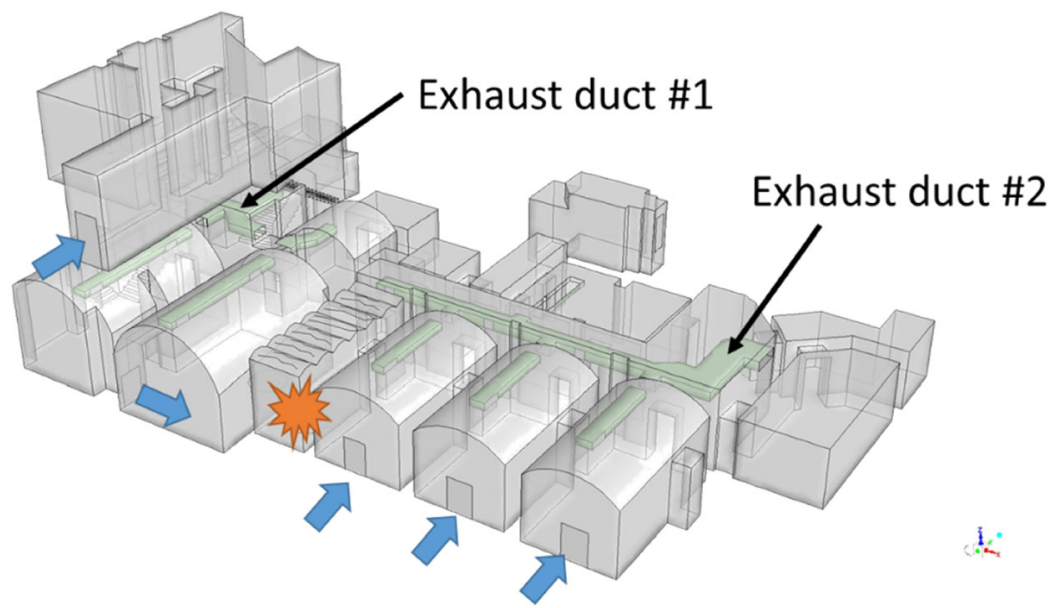

Figure 8. The numerical model of the cellar area, with the location of exhaust ducts, air supply and the fire used in the numerical analyses.

\section{Table 1}

Parameters of the smoke control systems compared in the case study

\begin{tabular}{lll}
\hline Parameter & Traditional system & Smart smoke control system \\
\hline Volumetric capacity $\left(\right.$ at $\left.20^{\circ} \mathrm{C}\right)$ & $10.4 \mathrm{~m}^{3} / \mathrm{s}$ & $10.4 \mathrm{~m}^{3} / \mathrm{s}$ \\
Mass flow rate $\left(\right.$ at $\left.20^{\circ} \mathrm{C}\right)$ & $12.48 \mathrm{~kg} / \mathrm{s}$ & $12.48 \mathrm{~kg} / \mathrm{s}$ \\
Volumetric capacity $\left(\right.$ at $\left.400^{\circ} \mathrm{C}\right)$ & $10.4 \mathrm{~m}^{3} / \mathrm{s}$ & $23.90 \mathrm{~m}^{3} / \mathrm{s}$ \\
Mass flow rate $\left(\right.$ at $\left.400^{\circ} \mathrm{C}\right)$ & $5.42 \mathrm{~kg} / \mathrm{s}$ & $12.48 \mathrm{~kg} / \mathrm{s}$ \\
\hline
\end{tabular}

Both traditional and smart smoke control systems were designed based on the architectural constrains of the building, Table 1. Both of the systems had ambient temperature exhaust capacity of $10.4 \mathrm{~m}^{3} / \mathrm{s}\left(2 \times 5.2 \mathrm{~m}^{3} / \mathrm{s}\right)$. However, the SSC was programmed to be able to reach up to $23.90 \mathrm{~m}^{3} / \mathrm{s}\left(2 \times 11.85 \mathrm{~m}^{3} / \mathrm{s}\right)$ at the maximum temperature of the smoke of $400^{\circ} \mathrm{C}$. The steering function of the SSC was defined as linear in the function of the average smoke temperature, separately for each smoke exhaust duct, as in [9]. The values presented are the capacities of an idealized system - in real world engineering during the MEP design a designer has to find a fan, that for calculated pressure losses in the system will provide this required capacity. The operating point of the fan is chosen at the ambient temperature, and will change with the change of temperature and operating pressure. Here we assume, that the shaft power of the fan will change along with the temperature and pressure. In consequence, the change of mechanical performance (volume flow) of the fan in the new operation point is negligible, compared to the effects of the introduction of the SSC. This simplification is based on practical 
experience with commercial testing of high-temperature fans [9] and is also a part of requirements of EN 12101-3 standard [11].

To illustrate this concept, a commercial fan selector tool was used to draw example curves of the same fan $\left(900 \mathrm{~mm}\right.$ diameter, $1440 \mathrm{rpm}, 9$ blades, $28^{\circ}$ blade angle) at $20^{\circ} \mathrm{C}$ (air density $1.20 \mathrm{~kg} / \mathrm{m}^{3}$ ) and $300^{\circ} \mathrm{C}$ (air density $0.62 \mathrm{~kg} / \mathrm{m}^{3}$ ), Fig. 9 . With the increase of the temperature the pressure changes from $600 \mathrm{~Pa}$ to $306 \mathrm{~Pa}$, shaft power from $9.69 \mathrm{~kW}$ to $4.97 \mathrm{~kW}$, but the volumetric flow remains almost unchanged. The curves presented on Fig. 9 were not used in the modelling, and the velocity inlet boundary condition for the exhaust fan is described in Chapter 4.4 .

\subsection{Numerical Model}

Computational Fluid Dynamics (CFD) analysis was performed with a well-known commercial code ANSYS ${ }^{\circledR}$ Fluent ${ }^{\circledR}$. Both traditional and Smoke Smart Control systems were investigated. CFD method is widely used in Fire Safety Engineering [1618] in the determination of smoke control performance in fire conditions. Among available CFD codes, a low-Mach implicit solver with LES turbulence model dedicated to fire-related phenomena exists - the Fire Dynamics Simulator (FDS) [19, 20]. This is a CFD model used in many fire and smoke-related analysis, with the best available validation documents $[21,22]$. However, similar to the work presented in [9] an active control over the exhaust fan boundary condition was required. Such control is possible in ANSYS ${ }^{\circledR}$ Fluent $^{\circledR}$ [23]. ANSYS allows dynamic alteration of boundary conditions through User Defined Functions (UDF) written in C language.

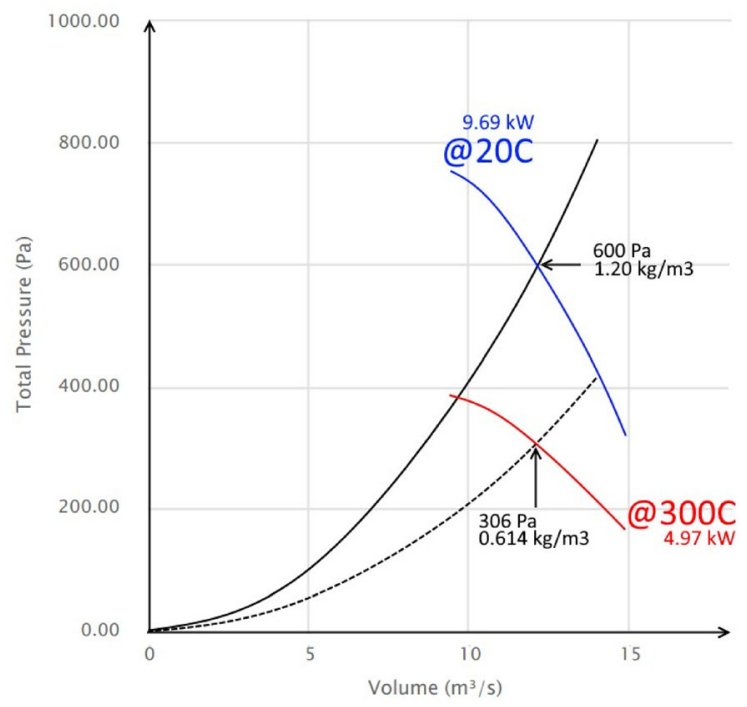

Figure 9. Example curves for the same fan, but at different temperatures $\left(20^{\circ} \mathrm{C}\right.$ and $\left.300^{\circ} \mathrm{C}\right)$. Operating pressure at $20^{\circ} \mathrm{C}$ was $600 \mathrm{~Pa}$. Drawing based on results from online commercial Fan Selector tool (https: //fanselector.flakłgroup.com). 
The use of this approach to model smart smoke control systems was described in [9]. Furthermore, ANSYS allows for almost unconstrained creation of complex geometry with unstructured meshes (tetrahedral, polyhedral) and efficient parallelization of the solution. Validation cases exist for ANSYS ${ }^{\circledR}$ Fluent ${ }^{\circledR}$ software in fire conditions and operation of fire ventilation systems [24-27] and it is mentioned as a viable too1 in some of smoke control standards [28].

The simulations were performed with a double-precision $3 \mathrm{D}$ solver in a segregate numerical scheme (second-order). The simulation was transient, and the turbulence was resolved with Realizable $\mathrm{k}-\varepsilon$ RANS model (in this case unsteadyRANS or URANS), modified for enhanced wall functions (shear stress in the near-wall region) and modified to account for buoyant forces. The radiative heat transfer was modelled with Discrete Ordinates model (162 discrete angles), and the heat transfer to the walls was modelled as a combination of convection and radiation (referred to as the third type boundary condition). The heat transfer within walls was modelled with the implementation of the Fourier law.

\subsection{Boundary Conditions}

The building walls were simplified and modelled as concrete, with a density of $2200 \mathrm{~kg} / \mathrm{m}^{3}$, the specific heat of $820 \mathrm{~J} / \mathrm{kg} * \mathrm{~K}$ and thermal conductivity of $1.20 \mathrm{~J} /$ $\mathrm{m}^{2} * \mathrm{~K}$. The roughness constant of walls (also in the shaft) was 0.05 and the mean roughness height of $0.01 \mathrm{~m}$.

The boundary condition on the exhaust fans was a velocity inlet, which means their velocity was independent of operating pressure, and dependant only on the UDF model (for the SSC). The smart smoke control UDF was written in C language [9] and was the representation of the flowchart shown on Fig. 7. Use of velocity inlet condition can be considered as a simplification of the fan modelling, as with this approach one cannot represent the changes to the fan curve with the change of temperature. Other approaches to fan modelling in ANSYS were summarized in [27]. Based on the requirements of EN 12101-3 [29] we can assume that the change in volumetric capacity of fan (due to change of curve) is not greater than $-10 \% /+25 \%$. Based on the results of preliminary fan selection (Fig. 9, Chapter 4.2), this change may be even smaller, and considered insignificant compared to the change we introduce with SSC approach. Furthermore, this simplification is justified as the scope of the paper is to identify if a hypothetical SSC system (with a dynamic increase of volumetric flow rate) can improve the tenability in an underground venue. The choice of a fan that meets these requirements is an engineering task, outside of the scope of this paper.

Air supply points were defined as a pressure-inlet boundary condition, which means that the static pressure determines the volumetric flow through the inlet in the proximity of the opening. A UDF was used to account for hydrostatic pressure at the openings.

The domain was discretised with an unstructured tetrahedral mesh. The size of the element was $10 \mathrm{~cm}$ in the proximity of the exhaust and inlet points, $15 \mathrm{~cm}$ at the seat of the fire and up to $30 \mathrm{~cm}$ in the remote areas of the domain. A growth function coefficient for the mesh was 1.15. This type of mesh was verified in an in- 
depth mesh sensitivity study for a fire of a similar size in a similar compartment in [30] and described in some good practice guidelines [31].

The fire was defined as a volumetric source of heat and mass. The evolution of the Heat Release Rate was defined with a usual " $\alpha t^{2}$ " relation, with the value of $\alpha=46.70 \mathrm{~W} / \mathrm{s}^{2}$, commonly known as the fast fire [11]. The Heat Release Rate was limited to $2,50 \mathrm{MW}$, and potential fire spread beyond the compartment of origin was not investigated. Conservative soot yield value of $Y_{\text {soot }}=0.1 \mathrm{~g} / \mathrm{g}$ was assumed [32].

For qualitative assessment, the performance of systems was compared with tenability criteria, among them: visibility of light-reflecting evacuation signs [33], the temperature of the smoke and the smoke layer height [34]. The Required Safe Evacuation Time (RSET) for this venue was calculated using computer evacuation model (buildingExodus) as explained in Sect. 4.1.

\section{Results and Discussion}

\subsection{Simulation Results for the Traditional Smoke Control}

In the case of the traditional solution, the performance of the smoke control system was generally not satisfactory, and would not be approved for project execution. As the limiting factors for the design were the available shaft space and a limited amount of air inlet points, further increase in the smoke exhaust capacity while complying with the requirements for the historical buildings was not possible. As shown in Fig. 10, the smoke has quickly filled a significant part of the cellar. Within the first $3 \mathrm{~min}$ of the simulation, the smoke fills compartments
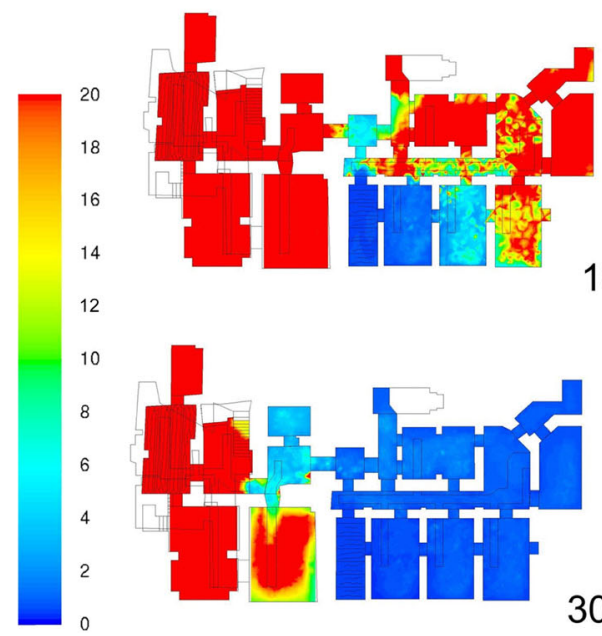

$180 \mathrm{~s}$

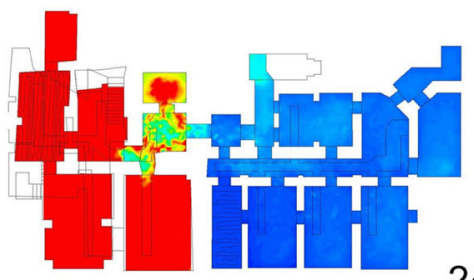

$240 s$

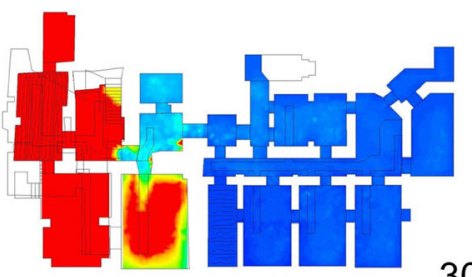

$300 \mathrm{~s}$

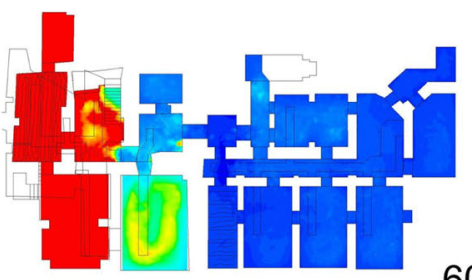

$600 \mathrm{~s}$

Figure 10. Visibility $(0-20 \mathrm{~m}$ ) for light reflecting signs ( $\mathrm{K}=3$ ) measured at the height 1,80 m above the floor of each of the compartments of the cellar affer 180 s, 240 s, 300 s and 600 s. The traditional smoke control system. 
neighbouring to the one with the fire, as well the vestibule located between the buildings. This means that the second evacuation route (through the other building) was cut off at this point. Within the next minute, the whole eastern wing of the building was filled with smoke, and in another minute the smoke fills part of the western wing. The smoke was penetrating the staircases. After 10 min steady state was achieved, with more than $75 \%$ of the cellar area filled with smoke. There was no smoke-free path to the source of the fire, so it can be assumed that the firefighting operations in these conditions are not possible.

Figure 11 presents the temperature plots in the same scenario. Due to quick development of the fire, the temperature of the smoke layer in the compartment of origin exceeds $290^{\circ} \mathrm{C}$ (radiant flux $>5 \mathrm{~kW} / \mathrm{m}^{2}$ at $\varepsilon=0.9$ ) in the compartment of origin within first $3 \mathrm{~min}$, and in the neighbouring compartment after $4 \mathrm{~min}$. Temperature exceeding $200^{\circ} \mathrm{C}$ (radiant flux $>2.5 \mathrm{~kW} / \mathrm{m}^{2}$ at $\varepsilon=0.9$ ) was observed in the third compartment after 4th minute, and in the fourth compartment and the evacuation routes after 5 th minute. The thermal conditions indicate that the fire can spread to the second compartment and that the evacuation was not possible in these conditions after $5 \mathrm{~min}$. The average temperature of the smoke removed through duct $\# 2$ was approximately $461{ }^{\circ} \mathrm{C}$.

Dependant on the acceptance criteria chosen, the Available Safe Evacuation Time (ASET) for this building was between $3 \mathrm{~min}$ and $5 \mathrm{~min}$, which is generally an unacceptable value compared to the RSET value of $5 \mathrm{~min}$ to $7 \mathrm{~min}$.
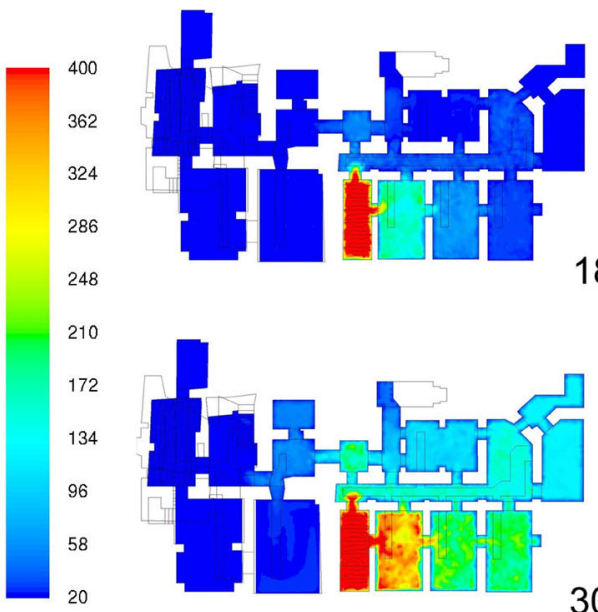

$180 \mathrm{~s}$

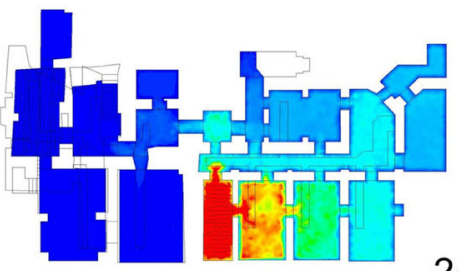

$240 s$

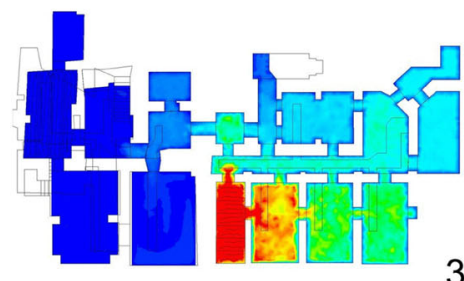

$300 \mathrm{~s}$

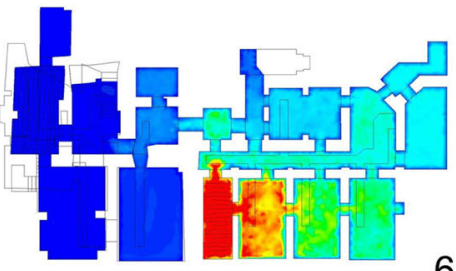

$600 \mathrm{~s}$

Figure 11. Temperature $\left(20-400^{\circ} \mathrm{C}\right)$ measured at the height of $1,80 \mathrm{~m}$ above the floor of each of the compartments of the cellar after 180 s, 240 s, 300 s and 600 s. The traditional smoke control system. 


\subsection{Simulation Results for the Smart Smoke Control}

Because of the signigicantly higher smoke exhaust rate (Table 1), the conditions observed in the smart smoke control scenario are improved compared to the traditional system. For SSC case, the visibility in smoke tenability criterion $(<10 \mathrm{~m})$ was exceeded only in the compartment of origin and the room next to it (in first $3 \mathrm{~min}$ ) and partially in the vestibule between buildings (after $4 \mathrm{~min}$ ), Fig. 12. The smoke spread was limited to this area, and steady-state was obtained in the $5^{\text {th }}$ minute. Even though the smoke did penetrate the ceiling area (smoke reservoir) of the eastern wing, the layer interface height was maintained sufficiently above the evacuation route. The passage between buildings was not accessible. However, at least one evacuation path was maintained in each of the wings. The smoke did not ventilate through staircases. In terms of the smoke layer temperature, the $290^{\circ} \mathrm{C}$ was exceeded only in the compartment of origin, and the temperature at the evacuation routes was maintained below $60^{\circ} \mathrm{C}$, Fig. 13. It is worth noting that only a small amount of smoke did move to the western wing of the cellar. Based on the accessibility of at least one evacuation route from each of the wings, low temperature of the smoke and the height at which the smoke layer was maintained, the Available Safe Evacuation Time in this scenario was above $10 \mathrm{~min}$.

The average temperature of the removed smoke of the Smart Smoke Control (measured in the duct $\# 2$ ) was $380^{\circ} \mathrm{C}$, and the average density of the removed smoke was $0.45 \mathrm{~kg} / \mathrm{m}^{3}$.
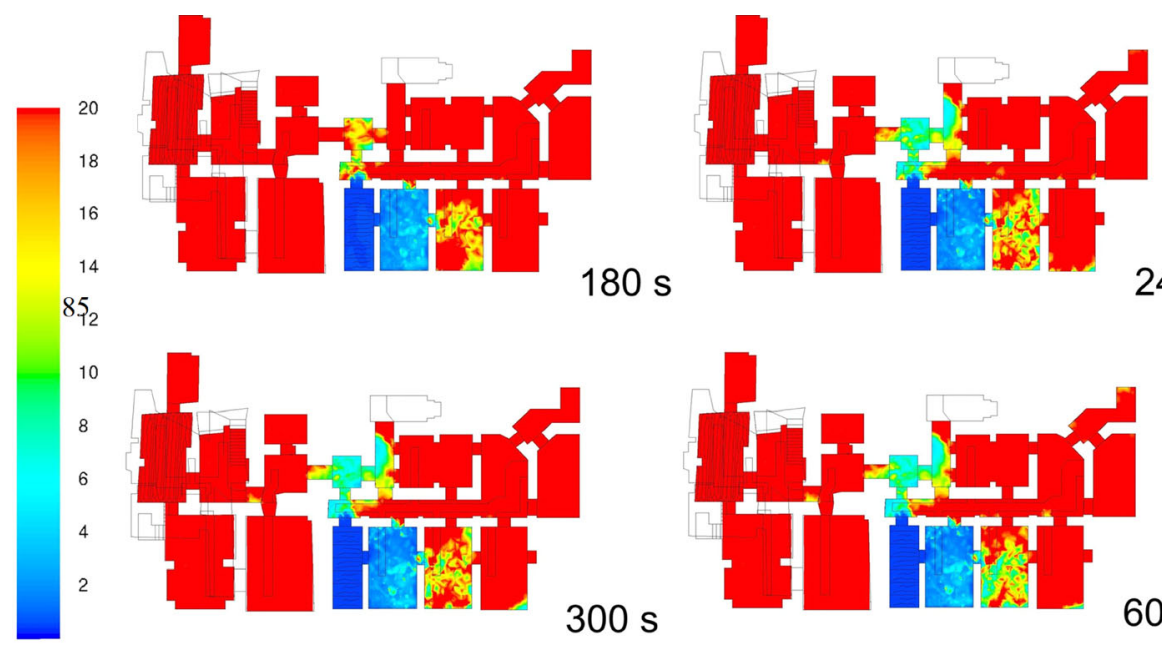

$240 \mathrm{~s}$

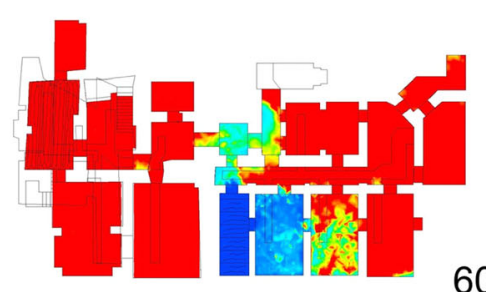

$600 s$

Figure 12. Visibility $(0-20 \mathrm{~m})$ for light reflecting signs $(K=3)$ measured at the height $1,80 \mathrm{~m}$ above the floor of each of the compartments of the cellar after 180 s, 240 s, 300 s and 600 s. The Smart Smoke Control system. 

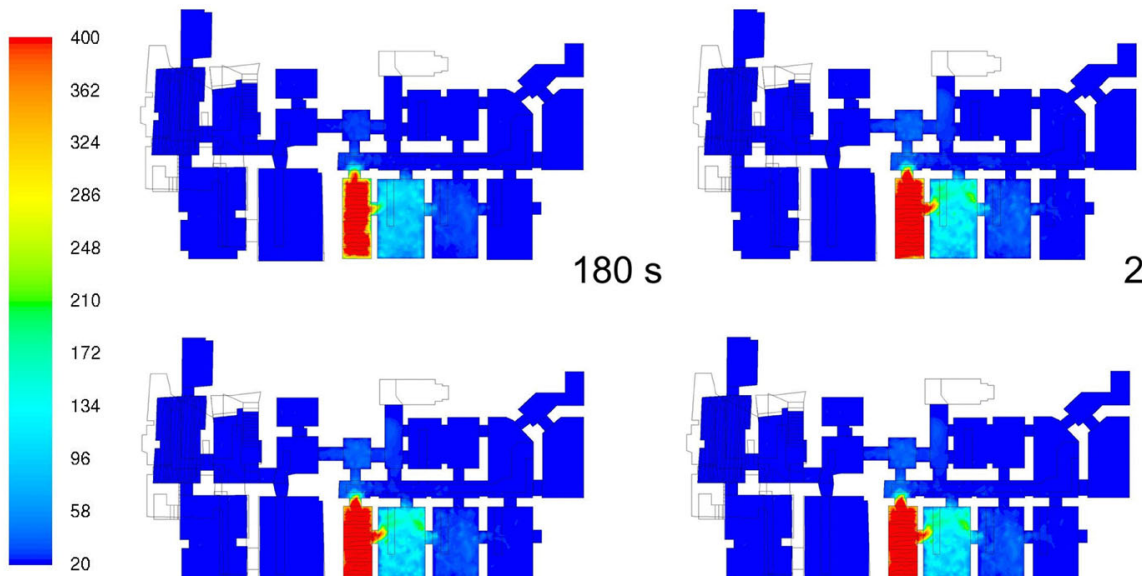

$180 \mathrm{~s}$

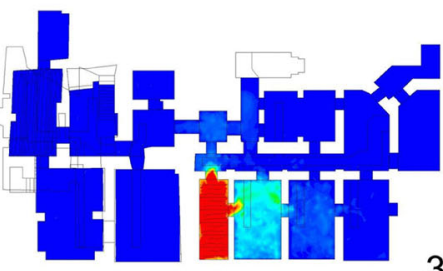

$300 \mathrm{~s}$

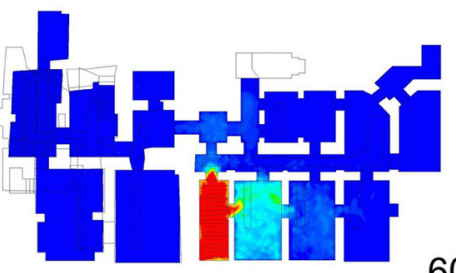

$600 \mathrm{~s}$

\section{Figure 13. Temperature $\left(20-400^{\circ} \mathrm{C}\right)$ measured at the height of $1,80 \mathrm{~m}$ above the floor of each of the compartments of the cellar after 180 s, 240 s, 300 s and 600 s. The Smart Smoke Control system.}

\section{Discussion}

The implementation of the SSC has resulted in the increase of the ASET from $3 \mathrm{~min}$ to $5 \mathrm{~min}$, to above $10 \mathrm{~min}$. The primary reason for this change is the increased exhaust capacity of the smart smoke control system in the eastern wing, which allowed to maintain the smoke in the smoke reservoir in a layer with interface high above the floor of the compartment, Fig. 14. For the traditional solution, the smoke generation was higher than the capacity of the system, and the smoke layer declined to a height between $1.20 \mathrm{~m}$ and $1.50 \mathrm{~m}$ (after $5 \mathrm{~min}$, in the most of the eastern wing). In the case of the SSC, the layer height is maintained at $2.00-2.30 \mathrm{~m}$, even $10 \mathrm{~min}$ into the analysis.

\subsection{Traditional System Smart Smoke Control System}

Measurements of the exhaust capacity are shown in Fig. 15, where the sharp increase of the volumetric flow in duct \#2 is clearly visible. In the case of the traditional solution, the volumetric exhaust rate at this duct is maintained as constant, and the mass flow rate decreases as the fire evolve. In the case of SSC, the mass flow rate is maintained as constant, and the volumetric flow rate is increased as the fire evolves. The increase of the volumetric capacity at this duct is $90 \%$ compared to the traditional solution. As in the SSC scenario, the smoke does not penetrate the western wing, the capacity of duct \#1 is unchanged with the evolution of the fire. This means that the overall increase in the volumetric capacity of the whole system is approx. 50\% higher than for the traditional solution. This increase is significantly higher than previously reported in a car park case study $(25-41 \%)$ [9]. 
Traditional system

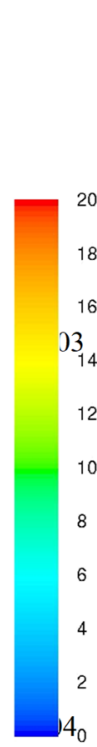

Smart Smoke Control system

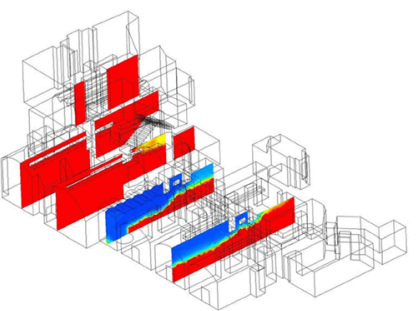

$180 \mathrm{~s}$
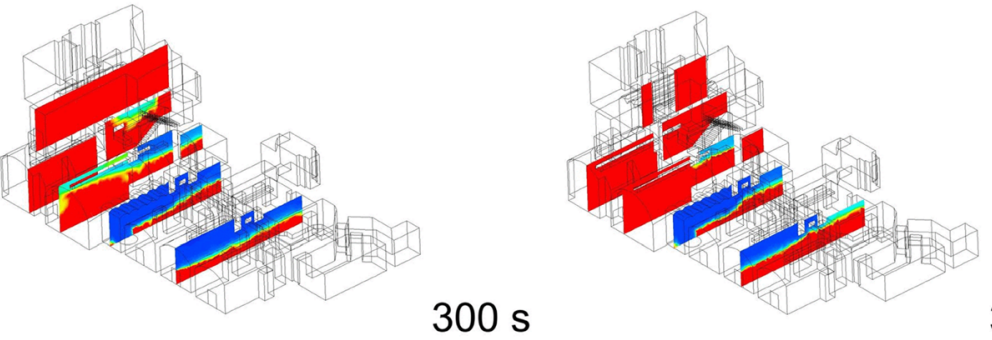

$300 \mathrm{~s}$

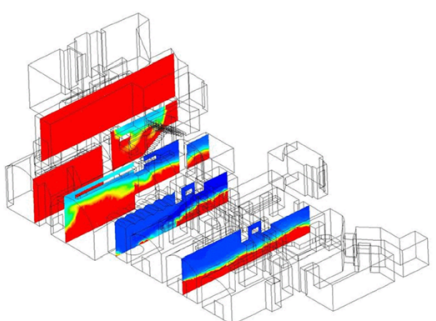

$600 \mathrm{~s}$

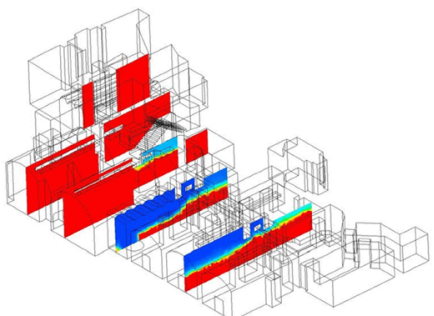

$600 \mathrm{~s}$

Figure 14. Visibility $(0-20 \mathrm{~m})$ for light reflecting signs $(K=3)$ measured in chosen vertical plots through the cellar after $180 \mathrm{~s}$, $300 \mathrm{~s}$ and $600 \mathrm{~s}$ for both verified smoke control solutions.
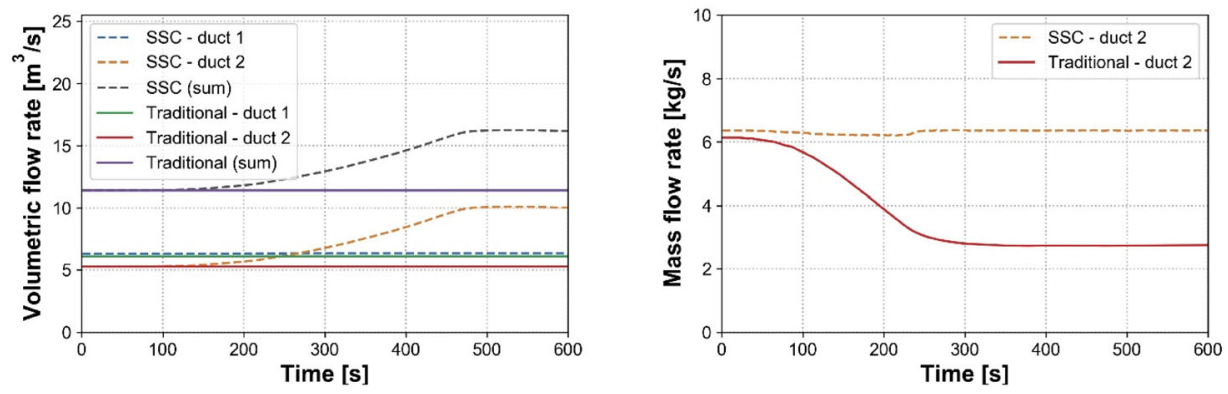

Figure 15. Volumetric and mass flow rate at chosen exhaust points in traditional and SSC scenarios. 


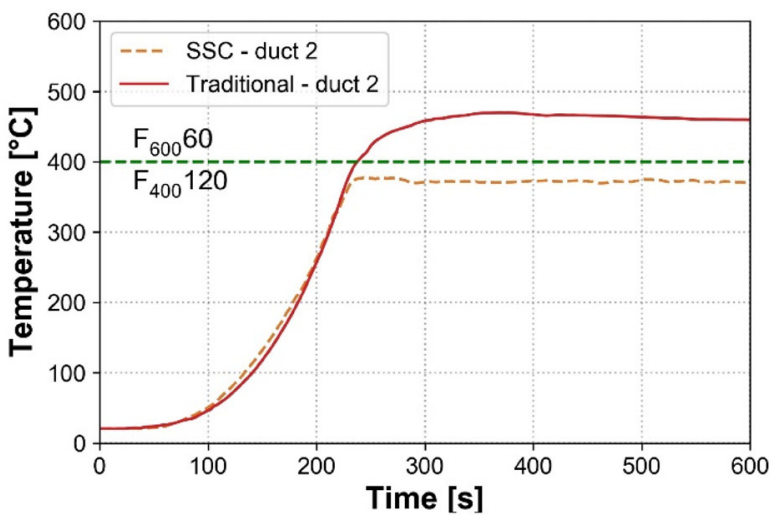

\section{Figure 16. Average smoke temperature measured at duct \#2 in traditional and SSC scenarios.}

Besides extending the ASET value, the implementation of SSC has caused a sharp decrease in the average temperature of the smoke removed at the peak value of HRR of the design fire, Fig. 16. What is noticeable is that the average temperature in the SSC in the duct \#2 was below $400^{\circ} \mathrm{C}$, which means that in this case smoke exhaust fans could be rated in class $\mathrm{F}_{400} 120$, while in traditional solution fans with a higher rating are necessary $\left(\mathrm{F}_{600} 60\right)$. To the best of the authors' knowledge, the differences in technology and costs between these two classes are profound and could exceed the associated costs with the installation of additional automation and a larger fan of the SSC system.

\section{Conclusions}

Smoke control in small, confined spaces located in underground levels of historic buildings can be considered as a significant challenge. The prime difficulties related to smoke control in such historic venues are limited duct and smoke reservoir space, an insufficient amount of air supply and unfavourable compartmentation of the area. This paper shown a possible improvement of the performance of smoke control in such areas, through a hypothetical temperature-adaptive smoke exhaust with variable exhaust rate, referred to as the smart smoke control (SSC). This solution could be useful for refurbishment of underground areas of historical building, that are converted to restaurant or music club venues.

The potential benefits of a hypothetical SSC were shown based on a case study of a historic cellar converted to a music club. A "traditional" solution for mechanical smoke and heat exhaust ventilation was developed based on the architectural constrains related to the duct-space and location of make-up air. The performance of this solution was verified through CFD simulations, deemed as unsatisfactory. The estimated ASET time of 3-5 min was lower, than the estimated RSET of 5-7 min. 
The use of SSC in this venue allowed for the removal of substantially larger amounts of hot air and smoke. This, in consequence, has significantly improved the smoke exhaust performance and tenability in the analysed space, without any change done to the ducting or building architecture. In the performed CFD simulation, the SSC system removed $90 \%$ more smoke in one of the wings of the building, and approx. 50\% more smoke overall (in the whole venue). The ASET time estimated for the SSC solution was estimated as ASET $>10 \mathrm{~min}$, and the smoke stratification was maintained in the venue. A surprising finding was that the average temperature of the smoke removed by the SSC was approx. $380^{\circ} \mathrm{C}$, compared to $472^{\circ} \mathrm{C}$ for the traditional solution. The temperature value of $400^{\circ} \mathrm{C}$ is a threshold value, at which a different type of fans must be used $\left(\mathrm{F}_{600} 60\right.$ instead of $\left.\mathrm{F}_{400} 120\right)$.

Based on the results of this numerical study it can be concluded, that a traditional smoke control system with exhaust rate similar to the one obtained with the SSC system, would provide similar effects related to the safety of occupants. However, due to technical, legal and economical constrains, provision of such a solution was not possible for the building in question.

In this paper we have investigated hypothetical performance of a SSC system. Due to simplifications introduced to the simulations (use of constant volumetric flow rate boundary condition instead of a fan-curve model) we did not address the change of the mechanical performance of the fan in increased temperatures (both traditional and SSC). For the reasons given in pt. 4.4, we consider these effects to be negligible compared to the change introduced by implementation of SSC solution. However, in real world engineering these considerations will be important to the MEP designer of the system, and also may reflect on the final cost of SSC solution. For the historic building shown in the study the implementation of a traditional system was not possible, thus we conclude that the SSC is a viable alternative, regardless of the cost effectiveness of the solution.

The presented Smart Smoke Control system is a new concept in the building smoke control, being a part of the "smart" revolution of safety systems. The positive results of the computational research justify further experimental research on these systems. The effects of change in fan curves with temperature must be included in the analysis to allow for simple choice of a fan fit for SSC solution. Furthermore, simple steering algorithms presented in this study may be further improved, to improve the robustness of the solution, and minimize the potential problems, that were identified in previous studies. Finally, the cost effectiveness of the SSC and its compatibility with different types of fixed suppression systems must be investigated. All of the above form the directions for future research on the SSC systems.

\section{Acknowledgements}

This paper is an extended version of a presentation presented at the 3rd SFPE Europe Conference in Malaga, 2019. 


\section{Open Access}

This article is licensed under a Creative Commons Attribution 4.0 International License, which permits use, sharing, adaptation, distribution and reproduction in any medium or format, as long as you give appropriate credit to the original author(s) and the source, provide a link to the Creative Commons licence, and indicate if changes were made. The images or other third party material in this article are included in the article's Creative Commons licence, unless indicated otherwise in a credit line to the material. If material is not included in the article's Creative Commons licence and your intended use is not permitted by statutory regulation or exceeds the permitted use, you will need to obtain permission directly from the copyright holder. To view a copy of this licence, visit http://creat ivecommons.org/licenses/by/4.0/.

\section{References}

1. Beller D, Sapochetti J (2000) Searching for answers to the Cocoanut Grove Fire of 1942. NFPA J 94:84-92

2. Fahy R, Proulx G, Flynn J (2011) The station nightclub fire - an analysis of witness statements. Fire Saf Sci 10:197-209. https://doi.org/10.3801/IAFSS.FSS.10-197

3. Corrêa BA, Bicho AL, Adamatti DF (2019) Multiagent systems and potential fields to smoke dispersion applied to evacuation simulations: the case of kiss nightclub. Appl Artif Intell 33:1008-1021. https://doi.org/10.1080/08839514.2019.1661577

4. Węgrzyński W, Sulik P (2016) The philosophy of fire safety engineering in the shaping of civil engineering development. Bull Polish Acad Sci Tech Sci 64:719-730. https:// doi.org/10.1515/bpasts-2016-0081

5. Cooper LY (1983) A concept for estimating available safe egress time in fires. Fire Saf J 5:135-144. https://doi.org/10.1016/0379-7112(83)90006-1

6. Krasuski A, Krenski K (2019) A-evac: the evacuation simulator for stochastic environment. Fire Technol 55:1707-1732. https://doi.org/10.1007/s10694-019-00827-7

7. Klote JH (2016) Smoke control. In: sfpe handbook of fire protection engineering. Springer, New York, pp 1785-1823

8. . CEN (2005) CEN/TR 12101-5:2005 Smoke and heat control systems. Guidelines on functional recommendations and calculation methods for smoke and heat exhaust ventilation systems

9. Węrzyński W (2017) Transient characteristic of the flow of heat and mass in a fire as the basis for optimized solution for smoke exhaust. Int J Heat Mass Transf 114:483500: https://doi.org/10.1016/j.ijheatmasstransfer.2017.06.088

10. Węgrzyński W (2018) Can smoke control become smart?. Arch Civ Eng 64:201-208. https://doi.org/10.2478/ace-2018-0040

11. EN 12101-3:2015-10 Smoke and heat control systems. Specification for powered smoke and heat control ventilators (Fans)

12. . NFPA (2015) NFPA 204 Standard for Smoke and Heat Venting 2015 Edition

13. VDI (2006) VDI 6019 Blatt 1 Ingenieurverfahren zur Bemessung der Rauchableitung aus Gebäuden Brandverläufe, Überprüfung der Wirksamkeit 
14. Gutiérrez-Montes C, Sanmiguel-Rojas E, Viedma A (2010) Influence of different makeup air configurations on the fire-induced conditions in an atrium. Build Environ . https://doi.org/10.1016/j.buildenv.2010.05.006

15. Rafinazari A (2015) Investigation of the effects of make-up air on atrium smoke conditions by Amir Rafinazari A thesis submitted to the Faculty of Graduate and Postdoctoral Affairs in partial fulfillment of the requirements for the degree of Doctor of Philosophy in

16. McGrattan K, McDermott R, Floyd J, Hostikka S, Forney G, Baum H (2012) Computational fluid dynamics modelling of fire. Int J Comut Fluid Dyn 26:349-361. https:// doi.org/10.1080/10618562.2012.659663

17. McGrattan K, Miles S (2016) Modeling fires using computational fluid dynamics (CFD). In: SFPE handbook of fire protection engineering. Springer, New York, pp 1034-1065

18. Merci B, Beji T (2016) Fluid mechanics aspects of fire and smoke dynamics in enclosures. CRC/Balkema, Taylor \& Francis Group, London, UK

19. McGrattan K, McDermott R, Vanella M, Hostikka S, Floyd J (2020) NIST Special Publication 1018-2. Sixth edition. Fire dynamics simulator. Technical Reference Guide. Volume 2: Verification. NIST, Gaithersburg, MD. https://doi.org/10.6028/NIST.SP.101 8

20. McGrattan K, Hostikka S, Floyd J, McDermott R, Vanella M (2020) NIST Special Publication 1018-1. Sixth Edition. Fire dynamics simulator. Technical Reference Guide. Volume 1: Mathematical model. NIST, Gaithersburg, MD. https://doi.org/10.6028/NIS T.SP.1018

21. Li YZ, Fan CG, Ingason H, Lönnermark A, Ji J (2016) Effect of cross section and ventilation on heat release rates in tunnel fires. Tunn Undergr Space Technol 51:414-423. https://doi.org/10.1016/j.tust.2015.09.007

22. Fan CG, Ji J, Gao ZH, Han JY, Sun JH (2013) Experimental study of air entrainment mode with natural ventilation using shafts in road tunnel fires. Int $\mathbf{J}$ Heat Mass Transf 56:750-757. https://doi.org/10.1016/j.ijheatmasstransfer.2012.09.047

23. ANSYS (2014) ANSYS fluent 14.5.0 - Technical Documentation

24. Tlili O, Mhiri H, Bournot P (2016) Empirical correlation derived by CFD simulation on heat source location and ventilation flow rate in a fire room. Energy Build 122:80 88. https://doi.org/10.1016/j.enbuild.2016.04.028

25. Bari S, Naser J (2005) Simulation of smoke from a burning vehicle and pollution levels caused by traffic jam in a road tunnel. Tunn Undergr Sp Technol 20:281-290. https:// doi.org/10.1016/j.tust.2004.09.002

26. Król M, Król A, Koper P, Wrona P (2017) Full scale measurements of the operation of fire ventilation in a road tunnel. Tunn Undergr Sp Technol 70:204-213. https:// doi.org/10.1016/j.tust.2017.07.016

27. Król A, Król M (2018) Study on numerical modeling of jet fans. Tunn Undergr Sp Technol 73:222-235. https://doi.org/10.1016/j.tust.2017.12.024

28. NFPA (2015) NFPA 92 standard for smoke control systems 2015 edition

29. BSI (2004) The application of fire safety engineering principles to fire safety design of buildings - part 6: human factors: life safety strategies - occupant evacuation, behavious and condition (sub-system 6). PD 7974-6

30. Wegrzyński W (2019) Partitions and the flow of smoke in large volume buildings. Archit Civ Eng Environ 11:155-164. https://doi.org/10.21307/acee-2018-016

31. VDI (2009) VDI 6019 Blatt 2 Ingenieurverfahren zur Bemessungder Rauchableitung aus Gebäuden Ingenieurmethoden, pp 1-27 
32. Węgrzyński W, Vigne G (2017) Experimental and numerical evaluation of the influence of the soot yield on the visibility in smoke in CFD analysis. Fire Saf J 91:389-398. https://doi.org/10.1016/j.firesaf.2017.03.053

33. Yamada T, Akizuki Y (2016) Visibility and human behavior in fire smoke. In: SFPE handbook of fire protection engineering. Springer, New York, pp 2181-2206

34. Huo R, Chow WK, Jin XH, Li YZ, Fong NK (2005) Experimental studies on natural smoke filling in atrium due to a shop fire. Build Environ 40:1185-1193. https://doi.org/ 10.1016/j.buildenv.2004.11.004

Publisher's Note Springer Nature remains neutral with regard to jurisdictional claims in published maps and institutional affiliations. 